\title{
Identificação do perfil químico das raízes de Euterpe oleracea Mart. empregando CG-EM
}

Euterpe oleracea Mart. é um importante palmeira cujas infusões de suas raízes são empregadas na medicina tradicional para o tratamento de várias doenças. Nesta perspectiva, este trabalho tem como objetivo investigar o perfil químico das raízes desta espécie, variedade açaí preto. As extrações, a transesterificação, a digestão e as reações de derivatização com BSTFA+1\%TMCS foram realizadas com agitação assistida por ultrassom. Os concentrados foram analisados por CG-EM, empregando uma coluna capilar ZB-5HT INFERNO $(30 \mathrm{~m} \times 0,25 \mathrm{~mm} \times 0,10 \mu \mathrm{m})$. De acordo com os resultados, foi possível identificar o perfil químico das raízes de Euterpe oleracea Mart, onde foram encontrados ácidos graxos insaturados, como o ácido oleico e palmitoleico, e ácidos fenólicos, como o ácido vanílico, $\mathrm{p}$ cumárico, cafeico e 4-hidroxibenzoico. A descrição do perfil metabólico nas raízes de E. oleracea Mart. abre perspectiva de investigação do uso destas raízes e suas possíveis atividades biológicas.

Palavras-chave: Açaí; Ácidos graxos; Ácidos fenólicos.

\section{Identification of the chemical profile of the roots of Euterpe oleracea Mart. by GC-MS}

\begin{abstract}
Euterpe oleracea Mart. is an important palm tree whose infusions of its roots are employed in traditional medicine for the treatment of various diseases. In this perspective, this work aims to investigate the chemical profile of the roots of this species, black acai variety. Extractions, transesterification, digestion and derivatization reactions with BSTFA + 1\% TMCS were performed with ultrasound-assisted agitation. The concentrates were analyzed by GC-MS, employing a capillary column ZB-5HT INFERNO $(30 \mathrm{~m} \times 0,25 \mathrm{~mm} \times 0.10 \mu \mathrm{m})$. According to the results, it was possible to identify the chemical profile of the roots of Euterpe oleracea Mart, where unsaturated fatty acids were found, such as oleic and palmitoleic acid, and phenolic acids, such as vanillyic acid, p-coumaric, caffeic and 4 hydroxybenzoic. The description of the metabolic profile in the roots of E. oleracea Mart. opens a perspective of investigating the use of these roots and their possible biological activities.
\end{abstract}

Keywords: Açaí; Fatty acids; Phenolic acids.

Topic: Química Agrícola e Ambiental

Reviewed anonymously in the process of blind peer.
Received: 08/06/2021

Approved: $24 / 06 / 2021$
Karen Albuquerque Dias da Costa (D)

Universidade Federal do Pará, Brasil

http://lattes.cnpq.br/8493677235656139

http://orcid.org/0000-0002-1363-303X

karenquimica123@yahoo.com.br

Jaisielle Kelem França Benjamim (id

Universidade Federal do Pará, Brasil

http://lattes.cnpq.br/7563800545443040

http://orcid.org/0000-0001-9111-8167

jaisequimica@gmail.com

Kyouk Isabel Portilho dos Santos (iD

Universidade Federal do Pará, Brasil

http://lattes.cnpq.br/1490440821822119

http://orcid.org/0000-0003-2843-791X

kyoukportilho@yahoo.com.br
André Silva dos Reis

Universidade Federal do Pará, Brasil

http://lattes.cnpq.br/3847913999600141

http://orcid.org/0000-0003-2202-7434

andrechemistry25@gmail.com

Alberdan Silva Santos (iD

Universidade Federal do Pará, Brasil

http://lattes.cnpq.br/5976702134131016

http://orcid.org/0000-0003-1863-176X

alberdan@ufpa.b
Referencing this:

COSTA, K. A. D.; BENJAMIM, J. K. F.; SANTOS, K. I. P.; REIS, A. S. SANTOS, A. S.. Identificação do perfil químico das raízes de Euterpe oleracea Mart. empregando CG-EM. Revista Ibero Americana de Ciências Ambientais, v.12, n.6, p.168-180, 2021. DOI:

http://doi.org/10.6008/CBPC2179-6858.2021.006.0015 


\section{INTRODUÇÃO}

A diversidade molecular de uma determinada planta é um fenômeno bioquímico dependente do potencial metabolômico que permite a formação de estruturas químicas responsáveis por atuar em variadas funções biológicas que asseguram o desenvolvimento fisiológico e a sobrevivência da espécie no meio ambiente, tais como: função de proteção (antialimentar de insetos), de atração de polinizadores, de adaptabilidade (agentes alelopáticos), de repelência de insetos); biocida (inseticidas e antimicrobianos) e principalmente, como medicamento (CARTEA et al., 2011; CHIRINOS et al., 2013; MARTíNEZ-CRUZ et al., 2014; MUNIYAN et al., 2016; PAJAKK et al., 2014). Esta característica relaciona tanto os metabólitos primários como os secundário e seu estudo permite a investigação das diferentes classes metabólicas presentes no metaboloma de um espécime (GRANATO et al., 2013). Neste sentido o metaboloma das raízes da espécie Euterpe oleracea Mart. (açaizeiro) foi estudado com o propósito de caracterizar o perfil químico desta parte da planta.

Euterpe oleracea Mart. (açaizeiro) é uma palmeira pertencente a Arecaceae, típica e muito disseminada em solos de várzea e igapó, principalmente nas zonas correspondentes ao Estuário Amazônico (SILVEIRA et al., 2017; SILVESTRE et al., 2017; WYCOFF et al., 2015), podendo ser encontrada em terra firme, e apresenta ocorrências em países como as Guianas, Panamá, Peru, Colômbia, Equador, Trindade Suriname e Venezuela (GARZÓN et al., 2017; PORTINHO et al., 2012). Esta espécie apresenta estirpe que pode atingir de 15 à 20 metros de altura e 12 à 18 cm de diâmetro (SILVA et al., 2017; DOMINGUES, 2017; YAMAGUCHI et al., 2015). Possui elevado valor cultural e grande potencial econômico para a Amazônia (NÓBREGA et al., 2012).

São conhecidas duas etnovariedades que se diferenciam em função dos teores de antocianinas no epicarpo e mesocarpo de seus frutos, onde o açaí preto, apresenta altas concentrações destas moléculas, resultando em frutos com coloração variando de roxo a preto, e o açaí branco, que não apresenta estas moléculas ou as apresenta em baixas concentrações, resultando em frutos com coloração verde a cinza (SILVEIRA et al., 2017; SILVESTRE et al., 2017; WYCOFF et al., 2015). Os frutos da Euterpe oleracea são drupáceos, esféricos, com massa variando de 1 à 2,5 gramas e diâmetro em torno de 1 a 2 centímetros (PEREIRA et al., 2014; TOWNSEND et al., 2001), sendo comestível somente o epicarpo e o mesocarpo dos mesmos.

As polpas de seus frutos são amplamente consumidas pela população local e em decorrência de suas propriedades nutricionais e os benefícios à saúde humana (atividade antioxidante) associados à sua ingestão tem se difundido para as demais regiões brasileiras e outros países como EUA, Japão, China e alguns países pertencentes à União Europeia (PEREIRA et al., 2016; PORTINHO et al., 2012; SILVESTRE et al., 2017). As vantagens da inserção dos frutos do açaizeiro na dieta são largamente relatadas na literatura, não obstante escassos são os trabalhos relatando o consumo do chá das raízes de açaí para fins medicinais.

O sistema radicular do açaizeiro é fasciculado (NASCIMENTO, 2008), constituído por um conjunto de raízes, finas, de coloração avermelhada, com dimensões semelhantes e originadas em um ponto central 
comum, podendo se alastrar por até $6 \mathrm{~m}$ de largura e emergir por até $40 \mathrm{~cm}$ de altura na base da estirpe (NASCIMENTO, 2008). Dentro da cultura popular amazônica estas raízes apresentam um importante papel no tratamento de várias doenças (BRUNSCHWIG et al., 2017).

Existem vários estudos que relatam a utilização do chá das raízes de açaí no tratamento de verminoses, de doenças do trato digestivo, como diarreias, doenças respiratórias, tosses e influenzas, doenças de natureza reumáticas e febres (BRUNSCHWIG et al., 2017). São relatadas também propriedades cicatrizantes, anti-inflamatórias e calmantes (FARIA, 2012; GOIS et al., 2016; NASCIMENTO, 2016). Entretanto são raros estudos identificando a composição química desta planta como medicinal. Nesta perspectiva, este trabalho tem como objetivo investigar o perfil químico das raízes da Euterpe oleracea Mart. (açaí preto) empregando as técnicas de cromatografia gasosa acoplada a espectrometria de massas (CG-EM).

\section{MATERIAIS E MÉTODOS}

\section{Reagentes}

Foram utilizados acetado de etila (A.C.S.), hexano (A.C.S.), dicloro metano (A.C.S.), metanol (A.C.S.), hidróxido de potássio 98\% (P.A.-A.C.S.), água ultra pura, ácido clorídrico 37\% (P.A.-A.C.S.), hidróxido de sódio 98\% (P.A.-A.C.S.) e N,O-bis(trimetilsilil) trifluoroacetamida + 1\% trimetilclorosilano (BSTFA + 1\% TMCS).

\section{Coleta das amostras}

As raízes da palmeira Euterpe oleracea Mart. (açaí preto) foram coletadas em uma região de mata nativa (latitude $1^{\circ} 15^{\prime} 5,134^{\prime \prime}$ S e longitude $48^{\circ} 16^{\prime} 35,861^{\prime \prime}$ O) pertencente à Vila de Pau D'Arco, pertencente ao município de Santa Barbara, Pará, Brasil (Registro SISGEN A246F9A).

\section{Processamento da amostra}

As raízes de Euterpe oleracea Mart. in natura foram secas em estufa com circulação de ar sob temperatura de $35{ }^{\circ} \mathrm{C}$ por três dias, em seguida foram trituradas em um ralador doméstico inox até a obtenção de um pó fino.

\section{Obtenção do extrato hexânico}

O extrato hexânico (extrato 1) foi obtido a partir de $100 \mathrm{mg}$ da amostra de raízes de Euterpe oleracea Mart. com $500 \mu \mathrm{L}$ de hexano, com auxílio de agitação assistida por ultrassom à temperatura de $35^{\circ} \mathrm{C}$, por 5 minutos. O sistema foi centrifugado à 10.000 RPM por 2 minutos à 10.000 RPM e, em seguida, o extrato 1 foi separado do precipitado (resíduo 1). Estes procedimentos foram realizados em triplicata.

\section{Transesterificação e derivatização do extrato hexânico}

Foram adicionados aproximadamente $10 \mathrm{mg}$ de extrato hexânico em tubos cônicos de $2 \mathrm{~mL}$ com tampa. Adicionou-se $100 \mu \mathrm{L}$ de uma solução saturada de hidróxido de potássio em metanol, agitou-se em 
vortex por 1 minuto e em banho com agitação assistida por ultrassom à $30^{\circ} \mathrm{C}$ por 2 minutos. Adicionou-se $200 \mu \mathrm{L}$ de hexano, agitou-se durante 1 minuto em vortex, centrifugou-se a 10.000 RPM durante 1 min e transferiu-se a fase orgânica para um segundo tubo, repetindo este processo em duplicata. Ao material residual, foi adicionado $110 \mu \mathrm{L}$ de $\mathrm{HCl} 2 \mathrm{~N}$, aguardou-se a neutralização do meio, observando a mudança de coloração do mesmo para branco, adicionou-se $300 \mu \mathrm{L}$ de uma solução Hexano:Diclorometano (1:1), agitouse em vortex por 1 minuto, centrifugou-se à 10.000 RPM por 1 minuto e transferiu-se a fase orgânica para o tubo que armazenava a fase orgânica da primeira etapa, este processo foi repetido em duplicata.

Evaporou-se $o$ solvente da fase orgânica, adicionou-se $50 \mu \mathrm{L}$ de $\mathrm{N}, \mathrm{O}$ bis(trimetilsilil)trifluoroacetamida $+1 \%$ trimetilclorosilano (BSTFA $+1 \%$ TMCS), agitou-se em vortex por 1 minuto, submeteu-se a banho maria, com agitação assistida por ultrassom durante 1 minuto a $30{ }^{\circ} \mathrm{C}$, evaporou-se o BSTFA, adicionou-se $500 \mu \mathrm{L}$ da solução Hexano:Diclorometano (1:1), transferiu-se a amostra para um frasco de vidro de $2 \mathrm{~mL}$ com tampa e septo. Injetou-se no GC-MS para análise do perfil lipídico.

\section{Hidrólise e extração de substâncias fenólicas, ácidos orgânicos e lipídios ligados à parede celular}

O resíduo 1, gerado após a extração com hexano, foi submetido a hidrólise alcalina, com agitação assistida por ultrassom, durante 30 minutos à temperatura de $60{ }^{\circ} \mathrm{C}$, por meio da adição de $400 \mu \mathrm{L}$ de $\mathrm{NaOH}$ 4M, em um fraco cônico de $2 \mathrm{~mL}$ com tampa. A homogeneização do sistema foi realizada através da agitação em vortex por 2 minutos. Em seguida, foram adicionados $500 \mu \mathrm{L}$ de $\mathrm{HCl} 6 \mathrm{M}$, agitou-se em vortex por 2 min e mensurou-se à pH 2. Novamente, o sistema foi submetido a agitação assistida por ultrassom durante 30 minutos à temperatura de $60^{\circ} \mathrm{C}$. Em sequência, foram realizadas três extrações com $500 \mu \mathrm{L}$ de acetato de etila (AcOEt), seguida de centrifugação à 10.000 RPM durante 2 minutos. $O$ extrato acetato de etila (extrato 2) foi separado e seco em $\mathrm{N}_{2}$. Estes procedimentos foram realizados em condições inertes.

\section{Derivatização do extrato acetato de etila}

Adicionou-se $200 \mu \mathrm{L}$ de N,O-bis(trimetilsilil) trifluoroacetamida $+1 \%$ trimetilclorosilano (BSTFA $+1 \%$ TMCS) ao extrato acetato de etila (extrato 2), agitou-se no vortex durante 2 minutos. Submeteu-se o sistema a agitação assistida por ultrassom por 30 minutos a temperatura de $60{ }^{\circ} \mathrm{C}$. Adicionou-se $500 \mu \mathrm{L}$ de AcOEt, agitou-se no vortex por 2 minutos, centrifugou-se durante 2 minutos à 10.000 RPM, transferiu-se o sobrenadante para um frasco de vidro com tampa e septo e realizou-se as análises por CG-EM.

\section{Análises do perfil químico das raízes de Euterpe oleracea Mart. por CG-EM}

As análises do perfil químico foram realizadas através de um Cromatógrafo de fase Gasosa (CG) ThermoScientific Trace 1300 acoplado a um espectrômetro de massa (EM) ThermoScientific MS-ISQ Single Quadrupolo com auto-amostrador Al 1310, equipado com coluna capilar ZB-5HT (30m x 0,25mm x 0,1 $\mu \mathrm{m})$, foi usado gás Hélio como carreador a um fluxo de $1 \mathrm{~mL} /$ minuto. Injeção de amostra de $1,0 \mu \mathrm{L}$ no modo Splitless. Para a análise do extrato hexânico (extrato 1), o injetor operou a $220{ }^{\circ} \mathrm{C}$ e a programação de temperatura do forno iniciou com $50^{\circ} \mathrm{C}$ até $200{ }^{\circ} \mathrm{C}\left(8^{\circ} \mathrm{C} /\right.$ minutos $)$, mantendo-se por 1 minutos, elevando-se 
até $300^{\circ} \mathrm{C}\left(15^{\circ} \mathrm{C} /\right.$ minutos), se mantendo por 5 minutos. Elevando-se novamente até $350^{\circ} \mathrm{C}\left(15^{\circ} \mathrm{C} / \mathrm{minutos}\right)$ e mantendo-se por mais 9 minutos. O MS-ISQ operou com interface a $280{ }^{\circ} \mathrm{C}$, fonte de ionização a $280{ }^{\circ} \mathrm{C}$, faixa de massa (40-1000 Da)(REIS, 2010). Para a análise do extrato acetato de etila (extrato 2), o injetor operou a $250{ }^{\circ} \mathrm{C}$ e a programação da temperatura do forno iniciou a $200{ }^{\circ} \mathrm{C}$, mantendo-se por 2 minutos, elevando-se até $300^{\circ} \mathrm{C}\left(20^{\circ} \mathrm{C} /\right.$ minutos $)$, se mantendo por 10 minutos. O MS-ISQ operou com interface a 275 ${ }^{\circ} \mathrm{C}$, fonte de ionização a $230{ }^{\circ} \mathrm{C}$, usando um atraso do solvente de 5 minutos, com faixa de massa (50-100Da). As identificações das substâncias foram realizadas através da comparação dos espectros de massa com os das bibliotecas comerciais NIST2011, WILEY2009, FAMES2011. O procedimento experimental deste trabalho é ilustrado na Figura 1.

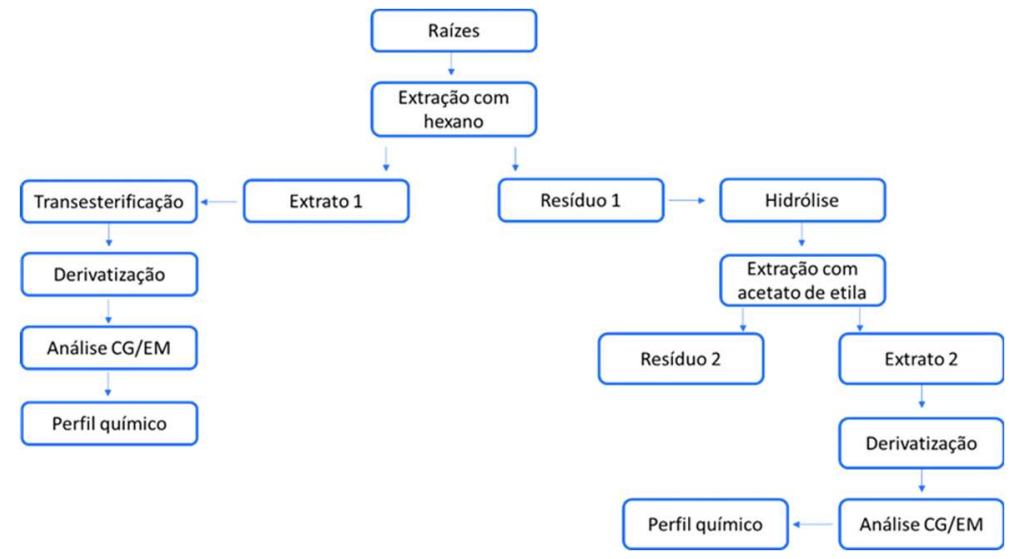

Figura 1: Fluxograma do procedimento experimental.

\section{RESULTADOS E DISCUSSÃO}

\section{Perfil químico do extrato hexânico das raízes de Euterpe oleracea Mart.}

O extrato hexânico (extrato 1) das raízes de Euterpe oleracea Mart. foi submetido ao processo de transesterificação, seguido de sililação com BSTFA+1\% TMCS e análise por CG-EM. A Figura 2 apresenta o cromatograma do perfil lipídico das raízes desta espécie.

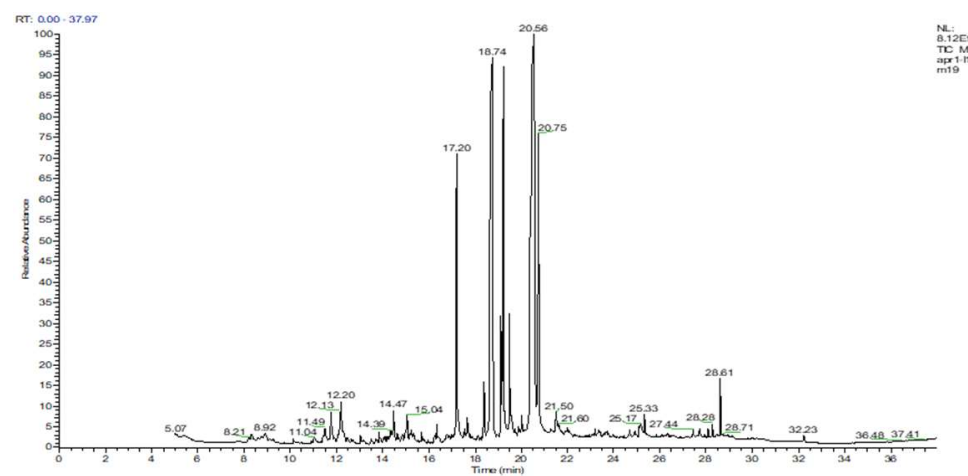

Figura 2: Cromatograma do perfil químico do extrato hexânico das raízes de Euterpe oleracea Mart.

Foram identificadas a presença de ácidos graxos saturados (AGS), monossaturados (AGM), poliinsaturados (AGP), um esteroide e um álcool. A Tabela 1 apresenta as 11 moléculas identificadas e seus respectivos tempos de retenção, concentração e fragmentos de massa. 
Tabela 1: Composição química do extrato hexânico das raízes de Euterpe oleracea Mart.

\begin{tabular}{lllll}
\hline Pico & TR & Substância & Área $(\%)$ & Íon $(\mathrm{m} / \mathrm{z})$ \\
\hline 1 & 8,31 & Glicerol & 0,74 & $73,147,205,218,293$ \\
2 & 16,33 & Ácido miristico & 0,94 & $73,117,132,285,286$ \\
3 & 17,2 & Ácido palmítico (metil éster) & 7,97 & $43,55,75,87,143$ \\
4 & 18,39 & Ácido palmitoleico & 1,55 & $41,55,69,117,129$ \\
5 & 18,74 & Ácido palmítico & 23,57 & $75,117,132,313,314$ \\
6 & 19,22 & Ácido oleico (metil éster) & 12,91 & $41,55,69,74,97$ \\
7 & 19,49 & Ácido esteárico (metil éster) & 3,82 & $43,55,70,83,143$ \\
8 & 20,56 & Ácido oleico & 37,90 & $75,117,129,145,339,354$ \\
19 & 20,75 & Ácido esteárico & 7,88 & $117,145,201,341,356$ \\
10 & 21,5 & Ácido araquidônico (metil éster) & 1,24 & $43,57,71,74,87$ \\
11 & 28,61 & $\alpha$-sitosterol & 1,47 & $129,255,357,396,498$ \\
\hline
\end{tabular}

O perfil lipídico das raízes de Euterpe oleracea Mart. é composto majoritariamente por AGM (52,36\%), sendo representado pelo ácido oleico em sua forma livre e metilada (ambos totalizando 50,81\%) e o ácido palmitoleico (1,55\%). Os AGS apresentaram um teor de $44,19 \%$, sendo representados pela soma das formas livres e metiladas dos ácidos: palmítico $(31,54 \%)$, esteárico $(11,70 \%)$ e miristico $(0,94)$. 0 ácido araquidônico e o $\alpha$-sitosterol foram os únicos AGP e esteroide identificados, respectivamente. A presença de ácidos graxos saturados e insaturados foram também relatadas em estudos do perfil de ácidos graxos nas sementes e no óleo da polpa desta espécie (SILVA et al., 2013; OKADA et al., 2011)

Os ácidos graxos são moléculas de cadeia normal que apresentam um grupamento carboxílico terminal. Participam de várias funções biológicas dentro do organismo humano, atuando como precursores de mensageiros químicos, como fonte energética e como componentes das membranas celulares (FERREIRA et al., 2011; GALÁN-ARRIERO et al., 2017). Ácidos graxos poli-insaturados, como o ácido araquidônico (ômega-6) e seus ésteres tem sido relatados como importantes imunomoduladores e agentes na prevenção de cardiopatias, aterosclerose, resistência à insulina, trombose e reguladores dos processos inflamatórios, haja vista que são percussores de metabólitos importantes como os tromboxanos, prostaglandinas e leucotrienos (GALÁN-ARRIERO et al., 2017; LIMA et al., 2000; NOVELLO et al., 2008).

Os ácidos graxos monoinsaturados como o ácido oleico (ômega-9) e o palmitoleico (ômega-7) tem sido alvo de vários estudos nos últimos anos. O ácido oleico não é essencial, podendo ser sintetizado a partir do ácido esteárico em uma reação mediada pela enzima $\Delta 9$-dessaturase (DELGADO et al., 2017), entretanto sua ingestão tem sido associada atividades biológicas como prevenção de doenças cardiovasculares (KOZŁOWSKA et al., 2016), prevenção de aterosclerose (AL-SHUDIEFAT et al., 2013; LACHMAN et al., 2015), modulação de processos imune e inflamatórios na pele (CARDOSO et al., 2011), a capacidade de modulação dos níveis de ansiedade em ratos, redução dos níveis de raiva e irritabilidade e redução da dor (GALÁNARRIERO et al., 2017). O ácido palmitoleico é um dos principais constituintes do fígado, da musculatura e do tecido adiposo humano (FRIGOLET et al., 2018; HUANG et al., 2010). Tem sido relatado como uma molécula capaz de combater o envelhecimento precoce, devido sua capacidade de regulação da produção de colágeno e antioxidante (HUANG et al., 2010; HYEJUNG et al., 2018). São atribuídas também a este ácido graxos propriedades anti-inflamatórias, regulação da insulina, proteção a esteatose hepática, doenças cardiovasculares e diabetes (ASTUDILLO et al., 2017; FRIGOLET et al., 2018; HYEJUNG et al., 2018; SOUZA et al., 2014). 
Os ácidos palmítico, esteárico e miristico são moléculas com pobre valor nutricional, porém em decorrência de sua não toxidade e sua estabilidade térmica e química e suas propriedades antimicrobianas tem sido aproveitados pela indústria farmacêutica para a produção de cosméticos para a pele como sabonetes, creme de barbear e loções e como veículo de drogas lipofílicas (CHEN et al., 2016; DANGAREMBIZI et al., 2015; HE et al., 2016; HURTADO-BENAVIDES et al., 2016; LATIBARI et al., 2015; LIU et al., 2012; SAGIRI et al., 2015). Ao ácido miristico são associadas também propriedades hepatoprotetora e anti-inflamatórias (PAN et al., 2010).

\section{Perfil químico do extrato acetato de etila das raízes de Euterpe oleracea Mart.}

As raízes de Euterpe oleracea Mart. foram submetidas a hidrólise alcalina e hidrólise ácida, extração com acetato de etila, derivatização com BSTFA+1\% TMCS e análise por CG-EM. A Figura 3 apresenta o cromatograma do perfil químico do extrato acetato de etila (extrato 2) das raízes de Euterpe oleracea Mart.

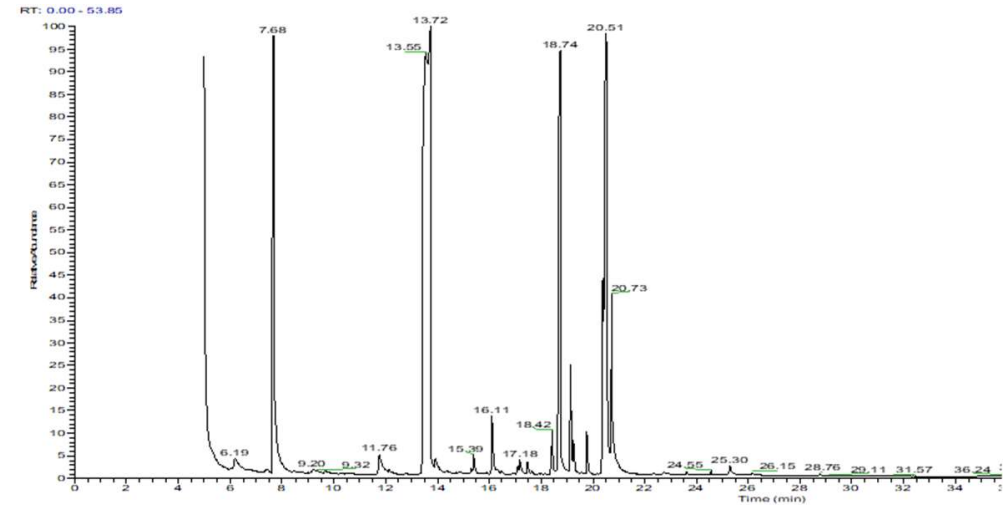

Figura 3: Cromatograma do perfil químico da biomassa das raízes de Euterpe oleracea Mart.

Foram identificadas a presença de substâncias fenólicas (50,38\%), AGP (18,84\%), AGS (13,19\%), AGM $(0,89 \%)$ e ácidos orgânicos (2,89\%), distribuídos em um total de 15 moléculas. A Tabela 2 apresenta estas substâncias, com seus tempos de retenção, concentração e seus respectivos fragmentos de massa.

Tabela 2: Perfil químico do extrato acetato de etila das raízes de Euterpe oleracea Mart.

\begin{tabular}{lllll}
\hline Pico & TR & Substância & Área $(\%)$ & Íon $(\mathrm{m} / \mathrm{z})$ \\
\hline 1 & 6,19 & Ácido oxálico & 1,13 & $43,73,75,77,147$ \\
2 & 7,41 & Ácido malônico & 0,21 & $43,45,73,75,147$ \\
4 & 9,20 & Ácido succínico & 0,35 & $45,73,75,77,147$ \\
5 & 11,76 & Ácido málico & 1,68 & $73,75,147,148,273$ \\
6 & 13,72 & Ácido 4-hidroxibenzóico & 51,15 & $73,43,267,223,282$ \\
7 & 15,39 & Ácido vanílico & 0,71 & $73,297,267,312,223$ \\
8 & 16,11 & Ácido protocatecuico & 1,87 & $45,73,193,355,370$ \\
10 & 17,48 & Ácido p-cumárico & 0,46 & $73,219,293,308$ \\
11 & 18,42 & Ácido palmitoleico & 1,04 & $55,73,75,117,129$ \\
12 & 18,74 & Ácido palmítico & 15,42 & $75,117,132,313,314$ \\
13 & 19,14 & Ácido 3,4-dihidroxifenil lático & 2,98 & $45,73,147,179,267$ \\
14 & 19,78 & Ácido cafeico & 0,96 & $45,73,219,396$ \\
15 & 20,51 & Ácido linoleico & 22,03 & $75,81,262,337,338$ \\
\hline
\end{tabular}

Os compostos fenólicos foram predominantes no extrato acetato de etila das raízes de Euterpe oleracea Mart. (extrato 2), dentre o ácido 4-hidroxibenzóico apresentou a maior concentração (51,15\%). Foram também identificados, porém em menores concentrações o ácido 3,4-dihidroxifenil lático (2,98\%), o 
ácido protocatecuico $(1,87 \%)$, o ácido cafeico $(0,96 \%)$, o ácido vanílico $(0,71 \%)$ e o ácido para cumárico $(0,46 \%)$.

As substâncias fenólicas são metabólitos secundários com alta capacidade antioxidante, caracterizados pela presença de pelo menos um anel aromático ligado a um grupamento hidroxila (CHANDRASEKARA, 2019; OLIVEIRA et al., 2011; MARTÍNEZ-CRUZ et al., 2014; SCHULZ et al., 2016). São amplamente distribuídos no reino vegetal, podendo estar de maneira livre ou de maneira conjugada a outras moléculas, abrangendo estruturas simples e moléculas de alto grau de polimerização(CARTEA et al., 2011; CHANDRASEKARA, 2019; PAJA̧K et al., 2014). Sua ingestão está associada a prevenção de várias doenças associadas ao estrese oxidativo, como o câncer, envelhecimento precoce, doenças cardiovasculares, aterosclerose, enfermidades degenerativas como o Alzheimer e Parkinson (CARTEA et al., 2011; OLIVEIRA et al., 2011; KHANG et al., 2016; KOSIŃSKA et al., 2012; MARTÍNEZ-CRUZ et al., 2014; ROSA et al., 2016; TAJIK et al., 2017; XIA et al., 2013).

O ácido 4- hidroxibenzóico foi a principal substância fenólica observada no extrato acetato de etila das raízes de Euterpe oleracea Mart. Esta molécula tem sido associada a atividades antioxidantes, antimicrobianas e antifúngica (KHADEM et al., 2010; SZOPA et al., 2014). O ácido protocatecuico está presente na maioria das plantas e é um dos principais fenólicos da dieta humana. Tem sido relatado como detentor de propriedades antioxidantes, antidiabética, anticâncer, antifúngica, antiviral, anti-inflamatória, hepatoprotetora, cardioprotetora, antimicrobiana, antiproliferativa, antiulcerogênica, anti-idade, antifibrótica, analgésica, antiaterosclerótica e nefroativa (ADEFEGHA et al., 2015; KAKKAR et al., 2014; KHADEM et al., 2010; LENDE et al., 2011; LIU et al., 2016; STOJKOVIĆ et al., 2013; SZOPA et al., 2014; TANAKA et al., 2011). O ácido vanílico tem sido associado a propriedades anti-helmínticas, hepatoprotetora e antiofídicas (KHADEM et al., 2010; SZOPA et al., 2014).

O ácido cafeico e o ácido p-cumárico são ácidos hidroxicinâmicos presentes em uma grande variedade de frutas (uva, maçã, tomates), feijões, tubérculos e cereais(ABDEL-MONEIM et al., 2017; EKINCI AKDEMIR et al., 2017; PEl et al., 2016; SHARMA et al., 2017). O ácido cafeico é facilmente absorvido no trato digestivo e é apontado como um agente hepatoprotetor, anticâncer, anti-inflamatório, antioxidante, antigripal, antimicrobiano e útil na proteção de aterosclerose (KHAN et al., 2016; LIMA et al., 2016; PANG et al., 2016). O ácido p-cumárico, por sua vez, apresenta propriedades antioxidantes, anti-inflamatórias, neuroprotetoras, antimutagênico, anticarcinogênicas, ansiolíticas, hepatoprotetoras, nefroprotetoras, antiulcerogênica e proteção contra aterosclerose e diabetes(ABDEL-MONEIM et al., 2017; EKINCI AKDEMIR et al., 2017; PEl et al., 2016; SHARMA et al., 2017; YOON et al., 2014).

O ácido 3,4-dihidroxifenil lático, juntamente com o ácido cafeico, é um dos precursores do ácido rosmarínico que é uma molécula muito comum em plantas medicinais(JIANG et al., 2016; LIN et al., 2017), bem absorvida pelo trato gastrointestinal e que apresenta propriedades antioxidantes, neuroprotetoras, imunomoduladoras, anti-inflamatórias, nefroprotetoras e hepatoprotetoras(FONTELES et al., 2016; LIN et al., 2017; ZHANG et al., 2017).

Os ácidos fenólicos presentes na biomassa das raízes de Euterpe oleracea Mart. pertencem a classe 
dos ácidos benzoicos e aos ácidos hidroxicinâmicos, ambas as classes possuem atividade antioxidante, porém os ácidos hidroxicinâmicos apresentam um potencial antioxidante superior aos ácidos benzoicos, decorrente da dupla ligação presente em suas estruturas (DEGÁSPARI et al., 2004). Estes ácidos são abundantes nas plantas e podem ser encontrados de maneira livre ou ligados a parede celular como moléculas componentes da lignina, sendo possível sua identificação possível através da desconstrução da lignina através de hidrolise alcalina (CARTEA et al., 2011; CHOUGUI et al., 2013; HELENO et al., 2015; SOARES, 2002).

Foram identificadas a presença dos ácidos palmítico $(15,42 \%)$, palmitoleico $(1,03)$ e linoleico (22,83\%). A presença destes ácidos graxos no extrato acetato de etila, mesmo após o processo de extração dos compostos lipossolúveis com hexano, pode estar relacionada ao fato que durante o processo de hidrólise, os lipídios presentes na parede celular das raízes são liberados ao meio reacional e são extraídos conjuntamente com as demais substâncias presentes na amostra. O ácido linoleico é um ácido graxo essencial indicado pela literatura como responsável por melhorar a sensibilidade das células a insulina, reduzindo consequentemente os níveis de açúcar nas mesma e contribuindo para a prevenção da obesidade (BELURY et al., 2018; LACHMAN et al., 2015). São atribuídas também a prevenção de inflamações e doenças como aterosclerose, diabetes e câncer (YANG et al., 2015).

Foram identificadas em baixas concentrações a presença dos ácidos orgânicos málico (1,68\%), oxálico $(1,13 \%)$, succínico $(0,35 \%)$ e malônico $(0,21 \%)$, esta classe foram recentemente associadas atividades antioxidantes e antimicrobianas (ALMASOUD et al., 2016; QUIROGA et al., 2019).

\section{CONCLUSÕES}

As raízes de Euterpe oleracea Mart. apresentam um perfil metabólico distribuído em dois grupos químicos importantes, pertencentes as classes dos lipídios, fenólicos e ácidos orgânicos. Estas substâncias são amplamente conhecidas por suas atividades biológicas capazes de atenuar e prevenir doenças cardiovasculares, cânceres, inflamações, doenças degenerativas e infecções por micro-organismos. Deste modo, a descrição do perfil metabólico nas raízes de E. oleracea abre perspectiva de investigação de uso destas raízes e suas atividades biológicas.

AGRADECIMENTOS: Ao Governo do Estado do Pará, a Secretaria Estadual de Educação do Pará e ao CNPQ pelas bolsas concedidas.

\section{REFERÊNCIAS}

ABDEL-MONEIM, A.; YOUSEF, A. I.; EL-TWAB, S. M. A.; REHEIM, E. S. A.; ASHOUR, M. B.. Gallic acid and p-coumaric acid attenuate type 2 diabetes-induced neurodegeneration in rats. Metabolic Brain Disease, v.32, n.4, p.1279-1286, 2017. DOI: http://doi.org/10.1007/s11011-017-0039-8

ADEFEGHA, S. A.; OBOH, G.; EJAKPOVI, I. I.; OYELEYE, S. I.. Antioxidant and antidiabetic effects of gallic and protocatechuic acids: a structure-function perspective. Comparative Clinical Pathology, v.24, n.6, p.1579-1585, 2015. DOI: http://doi.org/10.1007/s00580-015-2119-7
AL-SHUDIEFAT, A. A. R.; SHARMA, A. K.; BAGCHI, A. K.; DHINGRA, S.; SINGAL, P. K.. Oleic acid mitigates TNF- $\alpha$ induced oxidative stress in rat cardiomyocytes. Molecular and Cellular Biochemistry, v.372, n.1-2, p.75-82, 2013. DOI: http://doi.org/10.1007/s11010-012-1447-z

ALMASOUD, A.; HETTIARACHCHY, N.; RAYAPROLU, S.; KWON, Y. M.; MAUROMOUSTAKOS, A.. Inhibitory effects of lactic and malic organic acids on autoinducer type 2 (Al-2) quorum sensing of Escherichia coli 0157:H7 and Salmonella 
Typhimurium. LWT - Food Science and Technology, v.66, p.560-564, 2016. DOI: http://doi.org/10.1016/i.Iwt.2015.11.013

ASTUDILLO, A. M.; MEANA, C.; GUIJAS, C.; PEREIRA, L.; LEBRERO, P.; BALBOA, M. A.; BALSINDE, J.. Occurrence and biological activity of palmitoleic acid isomers in phagocytic cells. 2017. DOI: http://doi.org/10.1194/jlr.M079145

BELURY, M. A.; COLE, R. M.; SNOKE, D. B.; BANH, T.; ANGELOTTI, A.. Linoleic acid, glycemic control and Type 2 diabetes. Prostaglandins Leukotrienes and Essential Fatty Acids, v.132, p.30-33, 2018. DOI: http://doi.org/10.1016/j.plefa.2018.03.001

BRUNSCHWIG, C.; LEBA, L. J.; SAOUT, M.; MARTIAL, K.; BEREAU, D.; ROBINSON, J. C.. Chemical Composition and Antioxidant Activity of Euterpe oleracea Roots and Leaflets. International Journal of Molecular Sciences, v.18, n.1, p.61, 2017. DOI: http://doi.org/10.3390/ijms18010061

CARDOSO, C. R.; FAVORETO JUNIOR, S.; OLIVEIRA, L. L.; VANCIM, J. O.; BARBAN, G. B.; FERRAZ, D. B.; SILVA, J. S. Oleic acid modulation of the immune response in wound healing: A new approach for skin repair. Immunobiology, v.216, n.3, p.409-415, 2011. DOI:

http://doi.org/10.1016/j.imbio.2010.06.007

CARTEA, M. E.; FRANCISCO, M.; SOENGAS, P.; VELASCO, P.. Phenolic compounds in Brassica vegetables. Molecules, v.16, n.1, p.251-280, 2011. DOI:

http://doi.org/10.3390/molecules16010251

CHANDRASEKARA, A.. Phenolic acids. Encyclopedia of Food Chemistry, v.3, n.1, p.535-545, 2019. DOI: http://doi.org/10.1016/B978-0-08-100596-5.22395-0

CHEN, W.; WENG, W.. Ultrafine lauric-myristic acid eutectic/poly (meta-phenylene isophthalamide) form-stable phase change fibers for thermal energy storage by electrospinning. Applied Energy, v.173, p.168-176, 2016 DOI: http://doi.org/10.1016/i.apenergy.2016.04.061

CHIRINOS, R.; PEDRESCHI, R.; MIGNOLET, E.; LARONDELLE, Y.; CAMPOS, D.. Sacha inchi (Plukenetia volubilis): A seed source of polyunsaturated fatty acids, tocopherols, phytosterols, phenolic compounds and antioxidant capacity. Food Chemistry, v.141, n.3, p.1732-1739, 2013. DOI: http://doi.org/10.1016/j.foodchem.2013.04.078

CHOUGUI, N.; TAMENDJARI, A.; HAMIDJ, W.; HALLAL, S.; BARRAS, A.; RICHARD, T.; LARBAT, R.. Oil composition and characterisation of phenolic compounds of Opuntia ficusindica seeds. Food Chemistry, v.139, n.1-4, p.796-803, 2013. DOI: http://doi.org/10.1016/j.foodchem.2013.01.054

DANGAREMBIZI, R.; CHIVANDI, E.; DAWOOD, S.; ERLWANGER, K.; GUNDIDZA, M.; MAGWA, M. L.; MUREDZI, P.; SAMIE, A.. The fatty acid composition and physicochemical properties of the underutilised Cassia abbreviata seed oil. Pakistan Journal of Pharmaceutical Sciences, v.28, n.3, p.1005-1008, 2015.

DEGÁSPARI, C. H.; WASZCZYNSKY, N.. Propriedades Antioxidantes de Compostos Fenólicos. Visão Acadêmica, v.5, n.1, p.33-40, 2004. DOI: http://doi.org/10.5380/acd.v5i1.540
DELGADO, G. E.; KRAMER, B. K.; LORKOWSKI, S.; MARZ, W.; SCHACKY, C. V.; KLEBER, M. E.. Individual omega-9 monounsaturated fatty acids and mortality: The Ludwigshafen Risk and Cardiovascular Health Study. Journal of Clinical Lipidology, v.11, n.1, p.126-135.e5, 2017. DOI: http://doi.org/10.1016/j.jacl.2016.10.015

DOMINGUES, A. F. N.. Teor de Lipideos em caroços de Euterpe oleracea Mart. Boletim de Pesquisa e Desenvolvimento, v.115, p.1-59, 2017.

EKINCI AKDEMIR, F.; ALBAYRAK, M.; CALIK, M.; BAYIR, Y.; GULCIN, I.. The Protective Effects of $p$-Coumaric Acid on Acute Liver and Kidney Damages Induced by Cisplatin. Biomedicines, v.5, n.4, p.18, 2017. DOI: http://doi.org/10.3390/biomedicines5020018

FARIA, J. A. S.. Manejo de açaizais, riqueza florística e uso tradicional de espécies de várzeas do estuário Amazônico. Universidade Federal do Amapá, 2012.

FERREIRA, A. M.; SOUZA, B. M. V.; RIGOTTI, M. A.; LOUREIRO, M. R. D.. Utilização de ácidos graxos no tratamento de feridas: uma revisão integrativa da literatura nacional. Revista da Escola de Enfermagem da USP, v.46, n.3, p.752-760, 2011. DOI: http://doi.org/10.1590/s0080$\underline{62342012000300030}$

FONTELES, A. A. SOUZA, C. M.; NEVES, J. C. S.; MENEZES, A. P. F.; CARMO, M. R. S.; FERNANDES, F. D. P.; ARAÚJO, P. R.; ANDRADE, G. M.. Rosmarinic acid prevents against memory deficits in ischemic mice. Behavioural Brain Research, v.297, p.91-103, 2016. DOI:

http://doi.org/10.1016/j.bbr.2015.09.029

FRIGOLET, M. E.; GUTIÉRREZ-AGUILAR, R.. The Role of the Novel Lipokine Palmitoleic Acid in Health and Disease. Advances Nutrition, v.1, n.1, p.173-181, 2018. DOI: http://doi.org/10.3945/an.115.011130

GALÁN-ARRIERO, I.; SERRANO-MUNOZ, D.; GÓMEZSORIANO, J.; GOICOECHEA, C.; TAYLOR, J.; VELASCO, A; ÁVILA-MARTIN, G.. The role of Omega-3 and Omega-9 fatty acids for the treatment of neuropathic pain after neurotrauma. Biochimica et Biophysica Acta Biomembranes, v.1859, n.9, p.1629-1635, 2017. DOI: http://doi.org/10.1016/j.bbamem.2017.05.003

GARZÓN, G. A.; NARVÁEZ-CUENCA, C.; VINCKEN, J.; GRUPPEN, H.. Polyphenolic composition and antioxidant activity of açai (Euterpe oleracea Mart.) from Colombia. Food Chemistry, v.217, p.364-372, 2017. DOI: http://doi.org/10.1016/i.foodchem.2016.08.107

GOIS, M. A. F.; LUCAS, F.; COSTA, J. C. M.; MOURA, P. H. B.; LOBATO, G. J. M.. Ethnobotany of medicinal plant species in the treatment of disorders of the gastrointestinal system. Brazilian Journal of Medicinal Plants, Campinas, v.18, n.2, p.547-557, 2016. DOI: http://doi.org/10.1590/1983$084 X / 15 \quad 170$

GRANATO, E. M.; PAMPLONA, O. S.; PEREIRA, D. T. M.; MENDES, M. R. M.. Prospecção fitoquimica da espécie vegetal Trixis antimenorrhoea (Schrank) Kuntze. Revista Brasileira de Farmácia, v.94, n.2, p.130-135, 2013. 
HE, Y.; ZHANG, X.; ZHANG, Y. J.; SONG, Q.; LIAO, X. M.. Utilization of lauric acid-myristic acid/expanded graphite phase change materials to improve thermal properties of cement mortar. Energy and Buildings, v.133, p.547-558, 2016. DOI: http://doi.org/10.1016/j.enbuild.2016.10.016

HELENO, S. A.; MARTINS, A., QUEIROZ, M. J. R. P.; FERREIRA, I. C. F. R.. Bioactivity of phenolic acids: Metabolites versus parent compounds: A review. Food Chemistry, v.173, p.501513, 2015. DOI:

http://doi.org/10.1016/j.foodchem.2014.10.057

HUANG, C. B.; GEORGE, B.; EBERSOLE, J. L.. Antimicrobial activity of n-6, n-7 and n- 9 fatty acids and their esters for oral microorganisms. Archives of Oral Biology, v.55, n.8, p.555-560, 2010. DOI:

http://doi.org/10.1016/j.archoralbio.2010.05.009

HURTADO-BENAVIDES, A.; DORADO, D. A.; SÁNCHEZCAMARGO, A. D. P.. Study of the fatty acid profile and the aroma composition of oil obtained from roasted Colombian coffee beans by supercritical fluid extraction. Journal of Supercritical Fluids, v.113, p.44-52, 2016. DOI: http://doi.org/10.1016/i.supflu.2016.03.008

HYEJUNG, I. S.; HAN, G. H.; LEE, N.; CHA, J.; SON, Y.; KWON, J.. Omega-7 inhibits inflammation and promotes collagen synthesis through SIRT1 activation. Applied Biological Chemistry, v.61, n.4, p.433-439, 2018. DOI: http://doi.org/10.1007/s13765-018-0377-1

JIANG, J.; BI, H.; ZHUANG, Y.; LIU, S.; LIU, T.; MA, Y.. Engineered synthesis of rosmarinic acid in Escherichia coli resulting production of a new intermediate, caffeoylphenyllactate. Biotechnology Letters, v.38, n.1, p.81-88, 2016. DOI: http://doi.org/10.1007/s10529-015-1945-7

KAKKAR, S.; BAIS, S.. A Review on Protocatechuic Acid and Its Pharmacological Potential. ISRN Pharmacology, v.2014, p.19, 2014. DOI: http://doi.org/10.1155/2014/952943

KHADEM, S.; MARLES, R. J.. Monocyclic phenolic acids; hydroxy- and polyhydroxybenzoic acids: Occurrence and recent bioactivity studies. Molecules, v.15, n.11, p.79858005, 2010. DOI:

http://doi.org/10.3390/molecules15117985

KHAN, F. A.; MAALIK, A.; MURTAZA, G.. Inhibitory mechanism against oxidative stress of caffeic acid. Journal of Food and Drug Analysis, v.24, n.4, p.695-702, 2016. DOI: http://doi.org/10.1016/j.jfda.2016.05.003

KHANG, D. T.; DUNG, T. N.; ELZAAWELY, A. A.; XUAN, T. D. Phenolic Profiles and Antioxidant Activity of Germinated Legumes. Foods, v.5, n.4, p.27, 2016. DOI: http://doi.org/10.3390/foods5020027

KOSIŃSKA, A.; KARAMAC, M.; ESTRALLA, I.; HERNÁNDEZ, T.; BARTOLOMÉ, DYKES, G. A.. Phenolic compound profiles and antioxidant capacity of Persea americana mill. Peels and seeds of two varieties. Journal of Agricultural and Food Chemistry, v.60, n.18, p.4613-4619, 2012. DOI: http://doi.org/10.1021/if300090p

KOZŁOWSKA, M.; GRUCZYNSKA, E.; SCIBISZ, I.; RUDZINSKA, M.. Fatty acids and sterols composition, and antioxidant activity of oils extracted from plant seeds. Food Chemistry, v.213, p.450-456, 2016. DOI:

http://doi.org/10.1016/i.foodchem.2016.06.102

LACHMAN, J.; HEJTMÉNKOVÁ, A.; TÁBORSKÝ, J.; KOTIKOVA, Z.; PIVEC, V.; STRALKOVÁ, R.; VOLLMANNOVA, A.; BOJNANSKA, T.; DEDINA, M.. Evaluation of oil content and fatty acid composition in the seed of grapevine varieties. LWT - Food Science and Technology, v.63, n.1, p.620-625, 2015. DOI: http://doi.org/10.1016/j.lwt.2015.03.044

LATIBARI, S. T.; MEHRALI, M.; MEHRALI, M.; MAHLIA, T. M. I.; METSELAAR, H. S. C.. Fabrication and performances of microencapsulated palmitic acid with enhanced thermal properties. Energy and Fuels, v.29, n.2, p.1010-1018, 2015. DOI: http://doi.org/10.1021/ef502840f

LENDE, A. B.; KSHIRSAGAR, A. D.; DESHPANDE, A. D.; MULEY, M. M.; PATIL, R. R.; BAFNA, P. A.; NAIK, S. R.. Antiinflammatory and analgesic activity of protocatechuic acid in rats and mice. Inflammopharmacology, v.19, n.5, p.255-263, 2011. DOI: http://doi.org/10.1007/s10787-011-0086-4

LIMA, F. E. L.; MENEZES, T. N.; TAVARES, M. P.; SZARFARC, S. C.; FISBERG, R. M.. Acidos graxos e doenças cardiovasculares: uma revisão. Revista Nutrição, v.13, n.2, p.73-80, 2000. DOI: http://doi.org/10.1590/S1415$\underline{52732000000200001}$

LIMA, V. N.; OLIVEIRA-TINTINO, C. D. M.; SANTOS, E. S.; MORAIS, L. P.; TINTINO, S. R.; FREITAS, T. S.; GERALDO, Y. S.; PEREIRA, R. L. S.; CRUZ, R. P.; MENEZES, I. R. A.; COUTINHO, H. D. M.. Antimicrobial and enhancement of the antibiotic activity by phenolic compounds: Gallic acid, caffeic acid and pyrogallol. Microbial Pathogenesis, v.99, p.56-61, 2016. DOI: http://doi.org/10.1016/j.micpath.2016.08.004

LIN, S. Y.; WANG, Y.; CHEN, W.; LIAO, S.; CHOU, S.; YANG, C.; CHEN, C.. Hepatoprotective activities of rosmarinic acid against extrahepatic cholestasis in rats. Food and Chemical Toxicology, v.108, p.214-223, 2017. DOI: http://doi.org/10.1016/j.fct.2017.08.005

LIU, C.-H.; HUANG, H.-Y.. Antimicrobial Activity of CurcuminLoaded Myristic Acid Microemulsions against Staphylococcus epidermidis. Chemical and Pharmaceutical Bulletin, v.60, n.9, p.1118-1124, 2012. DOI: http://doi.org/10.1248/cpb.c12-00220

LIU, J.; MENG, C.; YAN, Y.; SHAN, Y, KAN, J.; JIN, C.. Protocatechuic acid grafted onto chitosan: Characterization and antioxidant activity. International Journal of Biological Macromolecules, v.89, p.518-526, 2016. DOI: http://doi.org/10.1016/j.ijbiomac.2016.04.089

MARTÍNEZ-CRUZ, O.; PAREDES-LÓPEZ, O.. Phytochemical profile and nutraceutical potential of chia seeds (Salvia hispanica L.) by ultra high performance liquid chromatography. Journal of Chromatography A, v.1346, p.43-48, 2014. DOI:

http://doi.org/10.1016/j.chroma.2014.04.007

MUNIYAN, R.; JAYARAMAN, G.. Lauric acid and myristic acid from Allium sativum inhibit the growth of Mycobacterium tuberculosis H37Ra: in silico analysis reveals possible binding to protein kinase B. Pharmaceutical Biology, v.54, n.12, p.2814-2821, 2016. DOI: http://doi.org/10.1080/13880209.2016.1184691 
NASCIMENTO, W. M. O.. Açaí: Euterpe oleracea Mart. Informativo Técnico Rede de Sementes da Amazônia, v.18, p.1-2, 2008.

NASCIMENTO, E. S.. Levantamento do conhecimento etnobotânico de comunidades ribeirinhas do estuário amapaense. Universidade Federal do Amapá, 2016.

NÓBREGA, J. A.; LIMA, E. P.; DANTAS NETO, J.. Diagnosis social-economic advantages of producers of açaí in natura: the municipalities of laranjal the jarí and victory of the Jari AP. Revista Verde de Agroecologia e Desenvolvimento Sustentável, v.7, p.23-29, 2012.

NOVELLO, D.; FRANCESCHINI, P.; QUINTILIANO, D. A.. A importância de ácidos graxos $\omega-3 \mathrm{E} \omega-6$ para a prevenção de doenças e na saúde humana. Revista Salus, v.2, n.1, p.77-87, 2008.

OKADA, Y.; MOTOYA, T.; TANIMOTO, S.; NOMURA, M.. A Study on Fatty Acids in Seeds of Euterpe oleracea Mart Seeds. Journal of Oleo Science, v.60, n.9, p.463-467, 2011. DOI: http://doi.org/10.5650/jos.60.463

OLIVEIRA, D. M.; BASTOS, D. H. M.. Biodisponibilidade de ácidos fenólicos. Química Nova, v.34, n.6, p.1051-1056, 2011. DOI: http://doi.org/10.1590/S010040422011000600023

PAJAK, P.; SOCHA, R.; GALKOWSKA, D.; ROZNOWSKI, J.; FORTUNA, T.. Phenolic profile and antioxidant activity in selected seeds and sprouts. Food Chemistry, v.143, p.300306, 2014. DOI:

http://doi.org/10.1016/j.foodchem.2013.07.064

PAN, P. H.; LIN, S.; OU, Y.; CHEN, W.; CHUANG, Y.; YEN, Y.; LIAO, S.; RAUNG, S.; CHEN, C.. Stearic acid attenuates cholestasis-induced liver injury. Biochemical and Biophysical Research Communications, v.391, n.3, p.1537-1542, 2010. DOI: http://doi.org/10.1016/j.bbrc.2009.12.119

PANG, C.; ZHENG, Z.; SHI, L.; SHENG, Y.; WEI, H.; WANG, Z.; JI, L.. Caffeic acid prevents acetaminophen-induced liver injury by activating the Keap1-Nrf2 antioxidative defense system. Free Radical Biology and Medicine, v.91, p.236-246, 2016. DOI:

http://doi.org/10.1016/j.freeradbiomed.2015.12.024

PEI, K.; OU, J.; HUANG, J.; OU, S.. p-Coumaric acid and its conjugates: Dietary sources, pharmacokinetic properties and biological activities. Journal of the Science of Food and Agriculture, v.96, n.9, p.2952-2962, 2016. DOI: http://doi.org/10.1002/jsfa.7578

PEREIRA, R. R.; ABREU, I. C. M. E.; GUERRA, J. F. C.; LAGE, N. N.; LOPES, J. M. M.; SILVA, M.; LIMA, W. G.; SILVA, M. E.; PEDROSA, M. L.. Açai (Euterpe oleracea Mart.) Upregulates Paraoxonase 1 Gene Expression and Activity with Concomitant Reduction of Hepatic Steatosis in High-Fat DietFed Rats. Oxidative Medicine and Cellular Longevity, v.1, n.1, p.1-13, 2016. DOI:

http://doi.org/10.1155/2016/8379105

PEREIRA, S. F. P.; MACIEL, A. E. S.; SANTOS, D. C.; MARES, E. K. L.; OLIVEIRA, G. R.; BITTENCOURT, J. A.; OLIVEIRA, J. S. Remoção de metais de águas superficiais usando carvão vegetal de açaí (Euterpe oleracea Mart.). In: INTERNATIONAL CONFERENCE ON ENGINEERING AND TECHNOLOGY EDUCATION, 13. Anais. 2014. p.401-405. DOI: http://doi.org/10.14684/INTERTECH.13.2014.397-401

PORTINHO, J. A.; ZIMMERMANN, L. M.; BRUCK, M. R.. Efeitos Benéficos do Açaí. International Journal of Nutrology, v.5, n.1, p.15-20, 2012

QUIROGA, P. R.; NEPOTE, V.; BAUMGARTNER, M. T.. Contribution of organic acids to $\alpha$-terpinene antioxidant activity. Food Chemistry, v.277, n.2018, p.267-272, 2019. DOI: http://doi.org/10.1016/j.foodchem.2018.10.100

REIS, A. S.. Aplicação de técnicas Lipidômica na investigação de tetranortriterpenos e esteoides presentes nas sementes de andiroba (Carapa guianensis Aubl.). Dissertação (Mestrado) - Universidade Federal do Pará, Belém, 2010.

ROSA, L. S.; SILVA, N. J. A.; SOARES, N. C. P.; MONTEIRO, M. C.; TEODORO, A. J.. Anticancer Properties of Phenolic Acids in Colon Cancer: A Review. Nutrition e Food Sciences, v.6, n.2, p.1-7, 2016. DOI: http://doi.org/10.4172/21559600.1000468

SAGIRI, S. S.; SINGH, V. K.; BANERJEE, I.; BASAK, P.. Stearic acid based oleogels: a study on the molecular, thermal and mechanical properties. Materials Science and Engineering $\mathbf{C}$, v.48, p.688-699, 2015. DOI:

http://doi.org/10.1016/i.msec.2014.12.018

SCHULZ, M.; BORGES, G. S. C.; GONZAGA, L. V.; COSTA, A. C O.; FETT, R.. Juçara fruit (Euterpe edulis Mart.): Sustainable exploitation of a source of bioactive compounds. Food Research International, v.89, p.14-26, 2016. DOI: http://doi.org/10.1016/j.foodres.2016.07.027

SHARMA, S. H.; CHELLAPPAN, D. R.; CHINNASWAMY, P.; NAGARAJAN, S.. Protective effect of $p$-coumaric acid against 1,2 dimethylhydrazine induced colonic preneoplastic lesions in experimental rats. Biomedicine and Pharmacotherapy, v.94, p.577-588, 2017. DOI: http://doi.org/10.1016/j.biopha.2017.07.146

SILVA, A. K. N.; BECKMAN, J. C.; RODRIGUES, A. M. C.; SILVA, L. H. M.. Avaliação da capacidade nutricional e capacidade antioxidante de compostos bioativos da polpa de açaí (Euterpe oleracea M.). Revista Brasileira de Tecnologia Agroindustrial, v.11, n.1, p.2205-2216, 2017. DOI: http://doi.org/10.3895/rbta.v11n1.2829

SILVA, J. J. M.; ROGEZ, H.. Avaliação da estabilidade oxidativa do óleo bruto de açaí (Euterpe oleracea) na presença de compostos fenólicos puros ou de extratos vegetais amazônicos. Química Nova, v.36, n.3, p.400-406, 2013. DOI: http://doi.org/10.1590/S0100-40422013000300009

SILVEIRA, T. F. F.; SOUZA, T. C. L.; CARVALHO, A. V.; RIBEIRO, A. B.; KUHNLE, G. G. C.; GODOY, H. T.. White açaí juice (Euterpe oleracea): Phenolic composition by LC-ESI-MS/MS, antioxidant capacity and inhibition effect on the formation of colorectal cancer related compounds. Journal of Functional Foods, v.36, p.215-223, 2017. DOI: http://doi.org/10.1016/i.jff.2017.07.001

SILVESTRE, W. V. D.; SILVA, P. A.; PALHETA, L. F.; OLIVEIRA NETO, C. F.; SOUZA, R. O. R. M.; FESTUCCI-BUSELLI, R. A.; 
PINHEIRO, H. A.. Differential tolerance to water deficit in two açaí (Euterpe oleracea Mart.) plant materials. Acta

Physiologiae Plantarum, v.39, n.1, p.4, 2017.

SOARES, S. E.. Ácidos fenólicos como antioxidantes. Revista Nutrição, v.15, n.1, p.71-81, 2002.

SOUZA, C. O.; TEIXEIRA, A. A. S.; LIMA, E. A.; BATATINHA, H. A. P.; GOMES, L. M.; CARVALHO-SILVA, M.; MOTA, I. T.; STRECK, E. L.; HIRABARA, S. M.; NETO, J. C. R.. Palmitoleic Acid (N-7) Attenuates the Immunometabolic Disturbances Caused by a High-Fat Diet Independently of PPAR. Mediators of Inflammation, v.1, n.1, p.1-12, 2014. DOI: http://doi.org/10.1155/2014/582197

STOJKOVIĆ, D. S.; ZIVKOVIC, S. J.; SOKOVIC, M.; GLAMOCLIJA, J.; FERREIRA, I. C. F. R.; JANKOVIC, T.; MAKSIMOVIC, Z.. Antibacterial activity of Veronica montana L. extract and of protocatechuic acid incorporated in a food system. Food and Chemical Toxicology, v.55, p.209-213, 2013. DOI: http://doi.org/10.1016/i.fct.2013.01.005

SZOPA, A.; EKIERT, H.. Production of biologically active phenolic acids in Aronia melanocarpa (Michx.) Elliott in vitro cultures cultivated on different variants of the Murashige and Skoog medium. Plant Growth Regulation, v.72, n.1, p.51-58, 2014. DOI: http://doi.org/10.1007/s10725-013$\underline{9835-2}$

TAJIK, N.; TAJIK, M.; MACK, I.; ENCK, P.. The potential effects of chlorogenic acid, the main phenolic components in coffee, on health: a comprehensive review of the literature.

European Journal of Nutrition, v.56, n.7, p.2215-2244, 2017. DOI: http://doi.org/10.1007/s00394-017-1379-1

TANAKA, T.; TANAKA, T.; TANAKA, M.. Potential Cancer Chemopreventive Activity of Protocatechuic Acid. Journal of Experimental and Clinical Medicine, v.3, n.1, p.27-33, 2011. DOI: http://doi.org/10.1016/j.jecm.2010.12.005

TOWNSEND, C. R.; COSTA, N. L.; PEREIRA, R. G. A.; SENGER,
C. C. D.. Características químico-bromatológicas do caroço de açaí. Comunicado Técnico Embrapa, v.193, n.1, p.3-8, 2001.

WYCOFF, W.; LOU, R.; SCHAUSS, A. G.; NEAL-KABABICK, J.; SABAA-SRUR, A. U. O.; MAIA, J. G. S.; TRAN, K.; RICHARDS, K. M.; SMITH, R. E.. Chemical and nutritional analysis of seeds from purple and white açaí (Euterpe oleracea Mart.). Journal of Food Composition and Analysis, v.41, p.181-187, 2015. DOI: http://doi.org/10.1016/i.jfca.2015.01.021

XIA, E.; HE, X.; LI, H.; WU, S.. Biological Activities of Polyphenols from Grapes. Polyphenols in Human Health and Disease, v.1, p.47-58, 2013. DOI: http://doi.org/10.1016/B978-0-12-398456-2.00005-0

YAMAGUCHI, K. K. L.; PEREIRA, L. F. R.; LAMARÃO, C. V.; LIMA, E, S.; VEIGA-JUNIOR, V. F.. Amazon acai: Chemistry and biological activities: A review. Food Chemistry, v.179, p.137-151, 2015. DOI:

http://doi.org/10.1016/i.foodchem.2015.01.055

YANG, B.; CHEN, H.; STANTTON, C.; ROSS, R. P.; ZHANG, H.; CHEN, Y.; CHEN, W.. Review of the roles of conjugated linoleic acid in health and disease. Journal of Functional Foods, v.15, p.314-325, 2015. DOI: http://doi.org/10.1016/j.jff.2015.03.050

YOON, J. H.; YOUN, K.; HO, C.; KARWE, M.; JEONG, W.; JUN, M.. p-coumaric acid and ursolic acid from corni fructus attenuated $\beta$-amyloid25-35-induced toxicity through regulation of the NF-KB signaling pathway in PC12 cells. Journal of Agricultural and Food Chemistry, v.62, n.21, p.4911-4916, 2014. DOI: http://doi.org/10.1021/jf501314g

ZHANG, M.; YAN, H.; LI, S.; YANG, J.. Rosmarinic acid protects rat hippocampal neurons from cerebral ischemia/reperfusion injury via the Akt/JNK3/caspase-3 signaling pathway. Brain Research, v.1657, p.9-15, 2017. DOI: http://doi.org/10.1016/i.brainres.2016.11.032

A CBPC - Companhia Brasileira de Produção Científica (CNPJ: 11.221.422/0001-03) detém os direitos materiais desta publicação. Os direitos referem-se à publicação do trabalho em qualquer parte do mundo, incluindo os direitos às renovações, expansões e disseminações da contribuição, bem como outros direitos subsidiários. Todos os trabalhos publicados eletronicamente poderão posteriormente ser publicados em coletâneas impressas sob coordenação da Sustenere Publishing, da Companhia Brasileira de Produção Científica e seus parceiros autorizados. Os (as) autores (as) preservam os direitos autorais, mas não têm permissão para a publicação da contribuição em outro meio, impresso ou digital, em português ou em tradução. 